\title{
Closed Humerus Fracture with Radial Nerve Palsy: Does it Warrant Primary Exploration?
}

\author{
Ahamad Shaheel Sultan ${ }^{a}$, A M George Kutty ${ }^{a}$, Mathunny Manesh Stephen ${ }^{\mathrm{a}}$, Mohammed Ashraf \\ a. Department of Orthopaedics, Government T.D Medical College, Alappuzha
}

Published on $1^{\text {st }}$ June 2020

\begin{abstract}
The question of primary exploration of radial nerve in cases of palsy associated with humerus fractures is still unanswered. We present a short case series of humerus fractures with radial nerve palsy where we found radial nerve transection warranting intervention.
\end{abstract}

Key Words: Radial Nerve, Nerve Transection, Radial Nerve Palsy, Transverse Fracture Humerus

\section{INTRODUCTION}

$\mathrm{H}$ umerus shaft fractures accounts to approximately $1-3 \%$ of total long bone fractures, amongst which $8-16 \%$ of them are associated with injuries to the radial nerve. ${ }^{1}$ Vast experiences from the Orthopaedic Surgeons \& recent guidelines advocate conservative treatment for all closed humeral shaft fractures with radial nerve palsy. These experiences \& studies are based on the understanding of the fact that most of the radial nerve palsy in closed fracture is due to Neuropraxia \& the nerve palsy in an Open Fractures is mostly due to Neurotemesis. Further it is believed that the Complete transection is usually seen in High velocity polytrauma or communition.

Here we present 4 cases from Government TD Medical College Hospital where patients sustained a closed, middle-third humeral shaft fracture with immediate radial nerve palsy. All four (4) patients underwent operative fixation of the humerus fracture, One due to an ipsilateral radius fracture, one being a bilateral humerus fracture, one due to an associated clavicle fracture \& other one a pathological fracture secondary to poliomyelitis.

\section{CASE REPORT}

\section{Case 1}

A 36-year-old man with no comorbidities presented to the Emergency \& Trauma department after Road Traffic
Accident sustaining high velocity closed fracture of Right Humerus. It was associated with Both Bone forearm fracture\& hence warranting for Surgical Management. On examination of his right upper extremity revealed a complete motor and sensory radial nerve palsy. Radiographs showed a right, middle-third, transverse humeral shaft fracture with Middle third both bone forearm fracture.

After Pre-Anaesthetic clearance both humerus shaft \& forearm fractures were planned for open reduction \& Internal fixation.

Using Posterior approach, Humerus was exposed and Radial nerve was identified. Radial nerve was entrapped \& transected between the fracture fragments which was then released. The fracture was stabilized using $4.5 \mathrm{~mm}$ DCP after isolation of the nerve. Forearm was fixed in the same sitting using 3.5mm DCP (Figures 1, 2, 3, 4).

\section{Case 2}

A 29-year-old lady with no co-morbidities was admitted in Orthopedic ward sustaining bilateral humerus shaft comminuted fracture with left sided radial nerve palsy after a high velocity road traffic accident. From our previous experience we found transection of the radial nerve in Ultrasonography.

After obtaining fitness for surgery, the patient was posted for bilateral humerus open reduction \& internal fixation with $4.5 \mathrm{~mm} \mathrm{LCP}$. Using posterior approach to the (left)

Cite this article as: Sultan AS, M GKA, Stephen MM, Ashraf M. Closed Humerus Fracture with Radial Nerve Palsy: Does it Warrant Primary Exploration? KJOrth. 2020 Jun 1;33(01):18-21.

Corresponding Author:

Dr A M GeorgeKutty, Additional Professor, Government T.D Medical College, Alappuzha, Kerala University of Health Sciences (KHUS) Mobile: 8310174626 E-mail: dr.shaheel@ymail.com

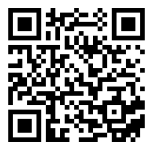

Access this Article Online

Scan this QR Code

https://doi.org/10.52314/kjo.2020.v33i01.10 


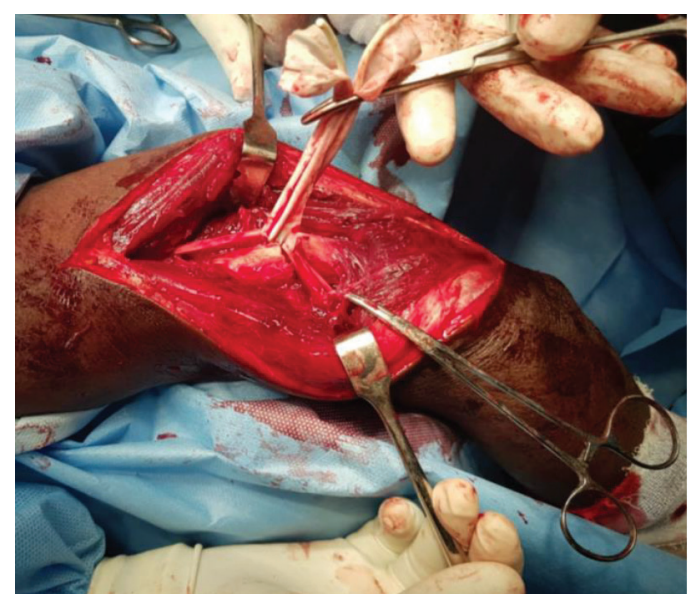

Figure 1. Entrapped Transected Radial Nerve

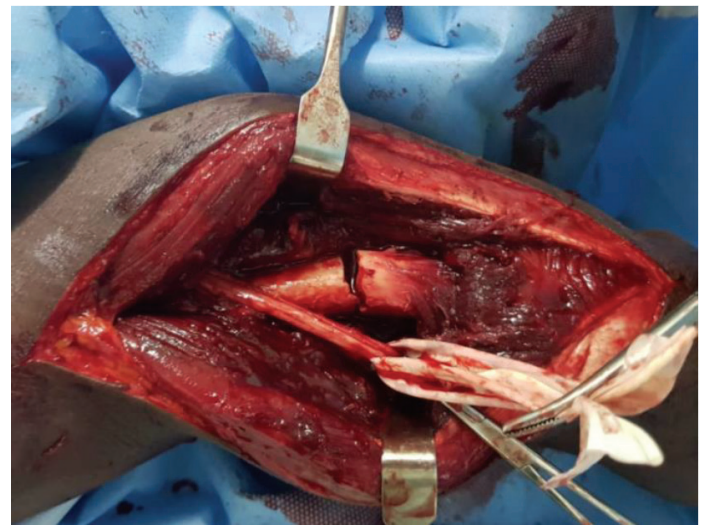

Figure 2. Released nerve parts

with an obvious deficits just assuming it to be a simple neuropraxia. Fixation may be an over-treatment without any surgical indication but definitely there is a huge difference in functional outcome if it misses out to be a complete transection. The fracture may unite but the nerve does not recover even after months. Studies have shown that even on electrophysiologic evaluation, the nerve and muscles exhibit the first signs of recovery only about 1 month before clinical recovery. ${ }^{7}$

The food for thought lies here. All 4 patients were an absolute indication for open reduction and internal fixation hence an intra-operative inspection found the transection. At any cost no recovery of the wrist and finger function would have happened.

Definitely it will be well debated that instead of embarking into an invasive procedure of open reduction and internal fixation it would scientifically make sense to go for a non-invasive investigation to differentiate between a neuropraxia to a complete transection. But nevertheless, any electrophysiological study will not reveal the difference in Neuropraxia or

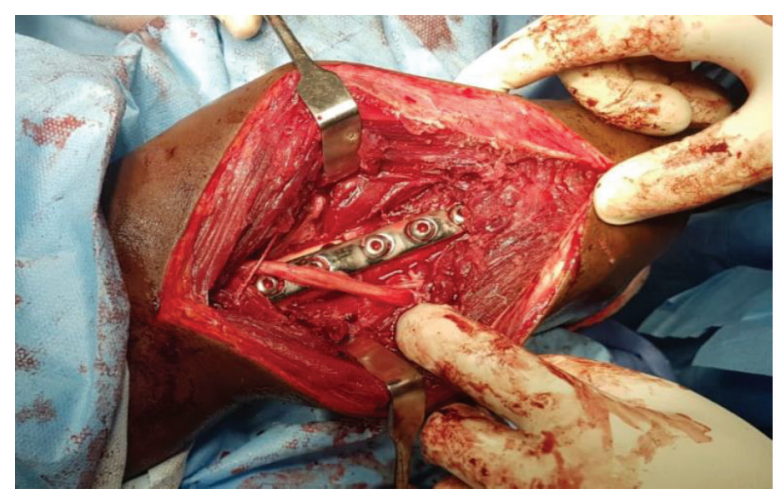

Figure 3. HUMERUS fixed with implant in-situ

humerus, the radial nerve was identified and was found to be transected. After achieving adequate reduction of the humerus it was fixed with $4.5 \mathrm{~mm}$ LCP. Right side humerus was also fixed in the same sitting with a similar implant.

The nerve was tagged with 6-0 Prolene and referred to the Department of Plastic Surgery for which the patient underwent primary repair. Patient is under follow-up with significant recovery of wrist and hand functions.

\section{Case 3}

A 38-year-old man with post-polio residual paralysis presented to Emergency Department of our College Hospital after sustaining a left humerus shaft fracture with no pre-existing Radial Nerve Palsy . Ultrasonography revealed complete transection of the Radial Nerve. The patient was posted for open reduction and internal fixation of the humerus shaft fracture with $3.5 \mathrm{~mm}$ DCP. During the posterior approach to the humerus, the radial nerve was seen to be completely transected. Once fracture was fixed he was referred to the department of plastic surgery where he underwent primary radial nerve repair. Finger and wrist are recovering. 


\section{Case 4}

A 46-year-old man hypertensive presented to the Medical College Hospital after Road Traffic Accident sustaining high velocity closed fracture of Right Humerus and Radius fracture. On examination of his right upper extremity revealed a complete motor and sensory radial nerve palsy. Radiographs showed a right, middle-third, transverse humeral shaft fracture with radius fracture.

After Pre-Anaesthetic clearance both humerus shaft \& radius was planned for open reduction \& Internal fixation.

Using Posterior approach, Humerus was exposed and Radial nerve was identified. Radial nerve showed complete transection. Fracture fragments of humerus was aligned and fixed with $4.5 \mathrm{~mm}$ narrow DCP. Radius underwent a closed fixation in the same sitting with an intra-medullary device. Despite adequate release and mobilization of the nerve, end to end repair was not possible and hence underwent cable graft repair using sural nerve.

\section{DISCUSSION}

95\% of humeral shaft fractures heal with non-operative management. ${ }^{2}$ Of fractures that require operative treatment, approximately $5-10 \%$ will result in nonunion. This statistics pushes a majority of the cases opting to be treated conservatively.

Slight Malunions \& shortening are very much acceptable in humerus. Up to $20^{\circ}$ of saggital anterior angulation and up to $30^{\circ}$ of varus coronal angulation do not hamper much of a normal function. The Classical functional cast bracing is preferable treatment for closed humeral shaft fractures.

Studies quote half of all open humeral shaft fractures have an accompanied radial nerve injury.,4 Any open fracture needs a lavage $\&$ primary debridement with stable fixation making it possible for intra-operative radial nerve inspection if its intact.

Latest Analysis shows recovery of Radial nerve function in $70 \%$ of patients with Closed Humerus fracture. $., 5,6$ Therefore in practice even with deficient function of wrist and hand due to Closed fracture with Radial Nerve palsy many of the Orthopaedic Surgeons prefer Closed treatment where radial nerve recovers but also the fracture unites without any risk of non-union as quoted by few studies.

Understanding the Principles of Conservative Management of humerus fixation and literature review for recovery of Radial Nerve definitely puts forward food for thought what if the nature of injury is not mere neuropraxia? Is it worth exploring the nerve not just to know the nature of injury but also would definitely give a better outcome from an early primary repair. Many of the times just taking into account of closed transverse fracture morphology we presume all these to be treated conservatively even completely transection when done immediately. Any Electrophysiological study will not reveal anytime early as at least one month from the clinical recovery.

Ultrasound may identify the discontinuity but is technically demanding requiring expertise. Other modalities of investigations require further reviews.

To the best of our knowledge, only two case reports have been reported in literature review s by leucht et al. We don't deny the fact that it is not uncommon. In both of their cases the surgeon approached through the anterolateral aspect of the humerus. All the 4 cases have been approached through posterior approach where the nerve is lying on the periosteum of the humerus mid-third where most of the transections are seen. Leucht et al also recommend posterior approach.

\section{CONCLUSION}

Considering our experience and Literature review showing 30 percent of outliers are diagnosed with complete transection warranting the need to explore and not to miss which at any cost would not recover. The fracture may unite but nerve will never recover.

We recommend Ultrasonography as a cheaper \& better diagnostic tool to diagnose nature of nerve injury for all humerus shaft fracture with radial nerve palsy.

Posterior approach is recommended for the fixation which helps to repair radial nerve in the same sitting.

\section{END NOTE}

\section{Author Information}

1. Dr Ahamad Shaheel Sultan, Consultant Orthopaedic Surgeon, Government T.D Medical College Alappuzha, Kerala University of Health Sciences (KUHS)

2. Dr A M George Kutty, Additional Professor, Department of Orthopaedics, Government T.D Medical College, Alappuzha, Kerala University of Health Sciences (KUHS)

3. Dr Mathunny Manesh Stephen, Assistant Professor, Department of Orthopaedics, Government T.D Medical College, Alappuzha, Kerala University of Health Sciences (KUHS)

4. Dr Mohammed Ashraf, Professor \& HOD, Department of Orthopaedics, Government T.D Medical College, Alappuzha, Kerala University of Health Sciences (KUHS)

Conflict of Interest: None declared

Study Funding: None 


\section{REFERENCES}

1. Foster RJ, Swiontkowski MF, Bach AW, Sack JT. Radial nerve palsy caused by open humeral shaft fractures. J Hand Surg Am. 1993 Jan;18(1):121-4.

2. Rutgers M, Ring D. Treatment of diaphyseal fractures of the humerus using a functional brace. J Orthop Trauma. 2006 Oct;20(9):597-601.

3. Kim DH, Kam AC, Chandika P, Tiel RL, Kline DG. Surgical management and outcome in patients with radial nerve lesions. J Neurosurg. 2001 Oct;95(4):573-83.

4. Shah JJ, Bhatti NA. Radial nerve paralysis associated with fractures of the humerus. A review of 62 cases. Clin Orthop Relat Res. 1983 Feb;(172):171-6.

5. Ekholm R, Ponzer S, Törnkvist H, Adami J, Tidermark J. Primary radial nerve palsy in patients with acute humeral shaft fractures. J Orthop Trauma. 2008 Jul;22(6):408-14.

6. Shao YC, Harwood P, Grotz MRW, Limb D, Giannoudis PV. Radial nerve palsy associated with fractures of the shaft of the humerus: a systematic review. J Bone Joint Surg Br. 2005 Dec;87(12):1647-52.

7. Postacchini F, Morace GB. Fractures of the humerus associated with paralysis of the radial nerve. Ital J Orthop Traumatol. 1988 Dec;14(4):455-64. 